\title{
Other short opinions/comments on moderate/low cancer genetic risk markers in medical practice and the article Genetic contribution to all cancers: the first demonstration using the model of breast cancers from Poland stratified by age at diagnosis and tumour pathology by Lubinski et al., Breast Cancer Res Treat 2008 Apr 15
}

\author{
Kristiina Aittomäki \\ Department of Clinical Genetics, Helsinki University Hospital, Helsinki, Finland \\ Corresponding author: Kristiina Aittomäki, MD, PhD, \\ Department of Clinical Genetics, Helsinki University \\ Hospital, POB 140, FIN-00029 HUS, Helsinki, Finland, \\ e-mail: kristiina.aittomaki@hus.fi
}

So far, we have not performed genetic testing on moderate cancer risk, such as CHEK2 testing for breast cancer. We feel that this would lead to a large number of the population being positive and that it is unlikely that all carriers would be offered surveillance. Furthermore, the economic burden from surveillance for moderate risk may not be acceptable in a situation where patients who already have cancer would not always be able to get the most expensive and most effective treatments available.

\section{Allan Spigelman}

Professor University of New South Wales, Surgical Professorial Unit, St Vincent's Hospital Clinical School, NSW, Australia

Corresponding author: Director Cancer Services St Vincent's and Mater Health Sydney, NSW, Australia, phone: +61283822354; +61 2 83822328, e-mail: aspigelman@stvincents.com.au

It is an interesting pilot study that requires replication on a larger scale.

\section{Walter Weber}

Betriebs- und Forschungslaboratorium, Zweckverband Landeswasserversorgung, Germany

Corresponding author: Medical Oncology, Heuberg 16, CH - 4051 Basel, e-mail: cancer@bluewin.ch
This is an important step towards defining genetic risk factors of breast cancer. As a medical oncologist I expect that downstream functions of such common genetic variants will be potential targets for new drugs [1]. Old drugs could also become new drugs [2]. Pharmacogenetics, the hereditary basis for inter-individual differences in drug effect, will predict patients at risk for extreme toxicity and altered efficacy of chemotherapy [3, 4].

\section{References}

1. Christensen K, Murray JC. What genome-wide association studies can do for medicine. N Eng J Med 2007; 356: 1094-1097.

2. Chong CR, Sullivan DJ Jr. New uses for old drugs. Nature 2007; 448: 645-646

3. Mc Leod HL. Genetic strategies to individualize supportive care. J Clin Oncol 2002; 20: 2765-2767.

4. Pandolfi PP. Breast cancer - loss of PTEN predicts resistance to treatment. N Eng J Med 2004; 351: 2337-2338.

\section{Vladimir Zajac}

Cancer Research Institute, Slovak Academy of Sciences, Laboratory of Cancer Genetics, Bratislava, Slovak Republic

Corresponding author: Cancer Research Institute, Slovak Academy of Sciences, Bratislava, Slovakia, e-mail:vladimir.zajac@savba.sk

It is practically impossible to find a paper in which the authors raise the basic issue - why there is such a high frequency of hereditary forms of cancer in the human population. I highly appreciate your approach and courage to go into this basic problem. I think that your hypothesis may bring a new impulse for the solution of this crucial question.

I have a feeling that at the present time human genetics, after a very dramatic period of approximately 20 years, is entering a period of recession. The reason is that we are not able to answer the aforementioned question.

Why do so many mutations in a very short part of human DNA result in various types of cancer diseases? This is mainly the case of the APC gene in the part of 
the MCR where there are concentrated about $70 \%$ of all APC germ-line mutations. The answer that this part of the DNA is special and is predisposed to mutation is not correct. We need to try to find another explanation. I am trying to do so.

I think that you are absolutely right that there should be something common in predisposition to all malignancies. Is this genetic polymorphisms? Probably yes.

Like many researchers who are interested in human genetics, I have a hypothesis as well. This idea has developed over many years and I suppose that it may open new perspectives into human genetics. At present I am working experimentally to confirm it. My idea is rather different from yours.

So, there are at the moment two hypotheses!!! Interesting!!!

And both are from Eastern Europe!!! It is funny that new impulses are coming from this, still underrated part of Europe.

Maybe this is the future. 